\title{
El comportamiento supererogatorio del imputado como base de atenuación de responsabilidad
}

\author{
Juan Pablo Mañalich Raffo*
}

\begin{abstract}
RESUMEN
El artículo pretende ofrecer una reconstrucción dogmática del fundamento y los presupuestos de las circunstancias atenuantes que se sustentan en el reconocimiento del carácter supererogatorio de determinadas formas de comportamiento procesal del imputado. Para ello se ofrece, en primer lugar, una taxonomía general de las circunstancias modificatorias previstas por los articulos 11, 12 y 13 del Código Penal, construida a partir de la distinción sistemática entre circunstancias concernientes al hecho punible y circunstancias ajenas al hecho punible. Respecto de esta base se clarifica entonces en qué consiste la especificidad de aquellas circunstancias-ajenas al hecho-que se encuentran referidas al comportamiento procesal del imputado, de lo que es posible extraer una determinación precisa de los criterios que deben gobernar la aplicación de las reglas que las instituyen.
\end{abstract}

Circunstancias atenuantes - supererogación - colaboración sustancial denuncia y confesión del delito

\section{The defendant's supererogatory behavior as mitigation basis}

\begin{abstract}
The paper offers a dogmatic reconstruction of the fundament and elements of the mitigating circumstances which are based upon the supererogatory trial behaviour of the accused. For that purpose, the paper presents a general taxonomy of so called 'modifying circumstances', fixed in arts. 11, 12 and 13 of the Penal Code, putting to work a systematic distinction between circumstances related and circumstances alien to the given offence. Upon this basis, the paper elucidates the distinctive nature of those circumstances which - being alien to the offence-concern the accused's trial behavior, so that the specific criteria that ought to guide the application of the corresponding rules can be properly determined.
\end{abstract}

Mitigating circumstances - supererogation - substantial collaboration confession of the offense

\footnotetext{
* Licenciado en Ciencias Jurídicas y Sociales de la Universidad de Chile. Abogado. Doctor en Derecho. Profesor asociado del Departamento de Ciencias Penales de la Facultad de Derecho, Universidad de Chile. Correo electrónico: jpmanalich@derecho.uchile.cl.

Artículo recibido el 13 de marzo de 2015 y aceptado para su publicación el 28 de agosto de 2015.
} 


\section{UNA TAXONOMÍA DE LAS ATENUANTES Y AGRAVANTES GENÉRICAS COMO FACTORES DE DETERMINACIÓN DE LA PENA}

\section{Circunstancias modificatorias intrínsecas versus circunstancias modificatorias extrínsecas}

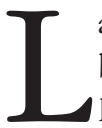

as circunstancias que la ley establece como atenuantes o agravantes de responsabilidad desempeñan una función polivalente como factores de determinación de la pena. De una parte, ellas pueden operar -en el nivel de la determinación legal de la pena- como criterios de concreción o alteración del marco penal previsto por la respectiva norma de sanción ${ }^{1}$. En este nivel, a su vez, es importante introducir una distinción entre aquellas circunstancias que por sí mismas tienen un impacto directo en esa operación de concreción o alteración del respectivo marco penal, por un lado, y aquellas cuya potencial incidencia queda determinada por las reglas que se ocupan de la concurrencia de una o más circunstancias atenuantes o agravantes, fijadas en los artículos 65 a 68 bis del Código Penal, por otro. Las primeras pueden ser denominadas "circunstancias de eficacia extraordinaria"; las segundas, "circunstancias de eficacia ordinaria" ${ }^{2}$. De otra parte, las (mismas) circunstancias modificatorias pueden operar -ahora en el nivel de la individualización judicial de la pena- como criterios de medición de la pena exacta, esto es, de individualización de la pena al interior del marco ya concretado, tal como lo prevén los artículos 69 y 70 del mismo código tratándose de la imposición de una pena privativa de libertad o de una pena pecuniaria.

Esta compleja función en tanto factor de determinación de la pena es potencialmente desempeñada por toda circunstancia modificatoria de responsabilidad, con independencia de que ella sea "genérica", esto es, prima facie pertinente respecto de cualquier especie de hecho punible, o bien "específica", esto es, prima facie pertinente solo respecto de determinada(s) especie(s) de hecho punible ${ }^{3}$. Ello no significa, empero, que en la

\footnotetext{
${ }^{1}$ Mañalich, J.P., “¿Discrecionalidad judicial en la determinación de la pena en caso de concurrencia de circunstancias atenuantes de la responsabilidad penal?", en Informes en Derecho. Doctrina Procesal Penal 2009, DPP, 2010, pp. 42 ss. Véase también Couso, J., "Comentario previo a los arts. 50 a 69 y 76 a 78 ", en Couso, J. y Hernández, H. (coords.), Código Penal Comentado, tomo I, Legal Publishing, 2011, pp. 511 ss.

${ }^{2}$ Mañalich, J.P., “¿Discrecionalidad judicial en la determinación de la pena en caso de concurrencia de circunstancias atenuantes de la responsabilidad penal?”, en Informes en Derecho. Doctrina Procesal Penal 2009, DPP, 2010, p. 46, con referencias ulteriores.

${ }^{3}$ Nótese que esta última clasificación es ciertamente gradual. Así por ejemplo, las agravantes previstas en los numerales 1 a 5 del art. 12, correctamente interpretadas en estas disposiciones, solo resultan aplicables tratándose de hechos constitutivos de delitos contra las personas, esto es, tipificados bajo el Título VIII del Libro II del Código Penal. Véase al respecto Cury, E., Derecho Penal Parte General, $7^{a}$ ed., Ediciones U. Católica, 2005, p. 472. A favor de tal interpretación ("restrictiva") hablan ante todo consideraciones sintácticas, complementadas por consideraciones sistemáticas. Pues siendo explícita la restricción del ámbito de pertinencia de la agravante del $\mathrm{N}^{\circ} 1$, al igual como sucede con la del $\mathrm{N}^{\circ} 5$, en el $\mathrm{N}^{\circ} 2$ se emplea la expresión "cometerlo", como componente de la cual el pronombre "lo" tendría que ser entendido como referido a un hecho de la misma clase expresamente identificada en el número anterior; en el No 3, por su parte, la cláusula final, concerniente a que el hecho dañe "a otras personas", sugiere que la agravante en cuestión solo es pertinente en relación con hechos consistentes en delitos contra las personas (en el sentido de la sistematización
} 
reconstrucción dogmática de la regulación no puedan ser introducidas determinadas distinciones ulteriores desde el punto de vista del específico fundamento del reconocimiento de la respectiva circunstancia como atenuante o agravante.

Esto último es especialmente importante en atención al significado que haya de atribuirse al principio de culpabilidad por el hecho como estándar de determinación de la pena. Pues un irrestricto compromiso de la regulación con la realización del principio de culpabilidad por el hecho qua estándar de determinación de la pena, tendría que traducirse en que como circunstancias modificatorias de responsabilidad solo vinieran en consideración atenuantes o agravantes en alguna medida concernientes a los presupuestos de fundamentación de la culpabilidad por el hecho que se atribuye al imputado, esto es, circunstancias intrínsecas al respectivo hecho punible. En tal caso, tendrían que quedar descartadas circunstancias que no guarden relación con esos mismos presupuestos, esto es, circunstancias extrínsecas al respectivo hecho punible.

Aun cuando expresada en otra terminología, tal distinción se encuentra explícitamente reconocida por la ley. En efecto, el inc. final del art. 343 del Código Procesal Penal prevé que, tratándose del pronunciamiento de una sentencia condenatoria, "el tribunal deberá resolver sobre las circunstancias modificatorias de responsabilidad penal” en la misma audiencia en que se comunique la decisión de absolución o condena, a menos que se trate de "circunstancias ajenas al hecho punible", en relación con las cuales el tribunal ha de abrir debate "inmediatamente después de pronunciada la decisión [de absolución y condena] y en la misma audiencia”. Si bien la disposición solo hace referencia, diferenciadamente, a las circunstancias ajenas al becho, es claro que la regulación procesal penal asume una distinción entre tales circunstancias y aquellas que cabría definir, correspondientemente, como circunstancias propias del hecho. Por estas últimas es factible entender, más precisamente, aquellas circunstancias modificatorias que se encuentran referidas a aspectos internamente conectados con la específica configuración del hecho punible de cuya imputación se trata. En cambio, cuentan como circunstancias modificatorias ajenas al hecho todas aquellas atenuantes o agravantes que no se encuentran referidas a aspectos concernientes a la configuración del hecho punible en cuestión.

Que la regulación procesal penal reconozca esta distinción entre circunstancias modificatorias propias del -o intrínsecas al- hecho punible en cuestión, por un lado, y circunstancias modificatorias ajenas -o extrínsecas-al mismo, por otro, muestra entonces que, al menos desde el punto de vista del régimen de las atenuantes y agravantes, bajo el derecho chileno el proceso de determinación de la pena no se encuentra irrestrictamente sometido al principio de culpabilidad por el hecho. Pues lo que distingue a las circunstancias modificatorias extrínsecas es, precisamente, su desacoplamiento de los presupuestos de constitución del respectivo hecho punible, presupuestos que a su vez

legislativa plasmada en el Libro II del Código Penal); finalmente, el ámbito de aplicabilidad de la agravante del ensañamiento, prevista en el $\mathrm{N}^{\circ} 4$, a pesar de no exhibir restricción alguna en atención al solo tenor de la disposición, también tendría que ser entendido como circunscrito a ese mismo ámbito delictivo, tanto en razón de su posición relativa al interior del catálogo del art. 12 como en consideración de la naturaleza de la agravante en cuestión. 
circunscriben el alcance del correspondiente reproche de culpabilidad. En tal medida, si la regulación otorga relevancia, como factores de determinación de la pena, a circunstancias que no tienen impacto alguno en la constitución del objeto del reproche manifestado por medio de la pena impuesta sobre el condenado, la regulación muestra, eo ipso, un compromiso solo parcial con el principio de culpabilidad por el hecho como estándar de determinación de la pena.

Si se examina, en lo que aquí interesa, el catálogo de circunstancias modificatorias establecidas en los artículos 11, 12 y 13 del CP, no resulta difícil determinar cuáles de ellas han de ser caracterizadas como intrínsecas y cuáles, en cambio, como extrínsecas. Para ello, sin embargo, resulta crucial hacer explícitos los criterios sobre la base de los cuales se encuentra trazada la diferenciación en cuestión, en los términos de la propia regulación legal.

En lo que respecta a las circunstancias que han de ser entendidas como intrínsecas, la regulación legal admite ser interpretada en el sentido de que la especificidad de tales atenuantes y agravantes consiste en que ellas en general aparecen referidas a los presupuestos del carácter específicamente delictivo del respectivo hecho punible, y más precisamente: o bien a los presupuestos del injusto, o bien a los presupuestos de la culpabilidad (por el injusto) ${ }^{4}$. Así por ejemplo, es claro que tanto la atenuante del artículo $11 \mathrm{~N}^{\circ} 10$ como la agravante del artículo $12 \mathrm{~N}^{\circ} 2$ tendrían que ser categorizadas como circunstancias (intrínsecas) relativas a presupuestos de la culpabilidad. Esto, porque ambas se encuentran referidas a aspectos concernientes al específico proceso de motivación involucrado en la perpetración del hecho punible en cuestión, en circunstancias de que el concepto de motivación se corresponde, en general, con una categoría pertinente en el contexto de la fundamentación de la culpabilidad en tanto escalón de la imputación. Y así también tendría que ser suficientemente claro, por su parte, que tanto la atenuante del artículo $11 \mathrm{~N}^{\circ} 3$ como la agravante del artículo $12 \mathrm{~N}^{\circ} 7$ han de ser categorizadas como circunstancias (intrínsecas) relativas a presupuestos del injusto. Pues una y otra se encuentran referidas a la específica posición del autor para con la persona de la víctima en la concreta situación del hecho 5 .

Ciertamente, es del todo posible que una determinada circunstancia, asimismo intrínseca, pueda exhibir una referencia variable tanto a los presupuestos del injusto como a los presupuestos de la culpabilidad. Bajo el catálogo aquí considerado, ello sucede con la atenuante por "eximente incompleta" del artículo $11 \mathrm{~N}^{\circ} 1$, cuya referencia al injusto o a la culpabilidad en tanto presupuestos de la responsabilidad dependerá de cuál sea la

\footnotetext{
${ }^{4}$ Al respecto Mañalich, J.P., "El delito como injusto culpable", en Revista de Derecho de la UACh, vol. 24, 2011, pp. 89 ss., 93 ss.

${ }^{5}$ Ello sugiere que, prima facie al menos, el mismo estatus tendría que ser predicable de la circunstancia "mixta" del parentesco, establecida en el art. $13 \mathrm{CP}$, cuyo efecto atenuante o agravante tendrá que ser determinado según cuáles sean "la naturaleza y los accidentes del delito". Nótese que de esto no se sigue que sea correcta la tesis según la cual la circunstancia del parentesco necesariamente tendría que operar como una agravante tratándose de un delito contra un bien jurídico altamente personal (o "contra la persona") y como una atenuante, en cambio, tratándose de un delito contra un bien jurídico puramente patrimonial. Véase sin embargo Etcheberry, A., Derecho Penal Parte General, $3^{\text {a }}$ ed., tomo II, Editorial Jurídica, 1997, pp. 46 s.
} 
naturaleza sustantiva que exhiba la eximente (de aquellas establecidas en el art. 10) de cuya "concurrencia incompleta" se trate: tratándose de una eximente que haya de ser entendida en el sentido de un fundamento de exclusión del injusto -verbigracia, como una causa de justificación-, esa "relatividad-al-injusto" se comunicará a la atenuante en cuestión; tratándose en cambio de una eximente a ser entendida en el sentido de un fundamento de exclusión de la culpabilidad, será la correspondiente "relatividad-a-laculpabilidad" lo que se comunique a la misma atenuante.

Las atenuantes y agravantes que por su parte admiten ser entendidas como extrínsecas también se dejan clasificar ulteriormente, con arreglo al criterio de si ellas están referidas al comportamiento anterior o posterior al hecho punible por parte del imputado. Así, tanto la atenuante de "irreprochable conducta anterior", prevista por el $\mathrm{N}^{\mathrm{o}} 6$ del art. 11, como las agravantes correspondientes a las diferentes variantes de reincidencia, establecidas en el $\mathrm{N}^{\circ} 14$, el $\mathrm{N}^{\circ} 15$ y el $\mathrm{N}^{\circ} 16$ del art. 12, constituyen circunstancias modificatorias (extrínsecas) relativas al comportamiento anterior del imputado. De otro lado, las atenuantes previstas en el $\mathrm{N}^{\circ} 7$, el $\mathrm{N}^{\circ} 8$ y el $\mathrm{N}^{\circ} 9$ del art. 11 se encuentran referidas al comportamiento posterior del imputado.

\section{El esquema clasificatorio resultante}

Ahora puede ser conveniente esquematizar la propuesta de clasificación precedentemente esbozada, tomando como base la distinción legal entre circunstancias atenuantes y agravantes "genéricas" 6 , comenzando por el catálogo de las circunstancias atenuantes:

\begin{tabular}{|c|c|c|c|}
\hline \multirow{11}{*}{ Atenuantes } & \multirow{7}{*}{ Intrínsecas } & \multirow{4}{*}{ Relativas al injusto } & Art. $11 \mathrm{~N}^{\circ} 1$ \\
\hline & & & Art. $11 \mathrm{~N}^{\circ} 3$ \\
\hline & & & Art. $11 \mathrm{~N}^{\circ} 4$ \\
\hline & & & Art. 13 \\
\hline & & \multirow{3}{*}{ Relativas a la culpabilidad } & Art. $11 \mathrm{~N}^{\circ} 1$ \\
\hline & & & Art. $11 \mathrm{~N}^{0} 5$ \\
\hline & & & Art. $11 \mathrm{~N}^{\circ} 10$ \\
\hline & \multirow{4}{*}{ Extrínsecas } & Relativas al comportamiento anterior del imputado & Art. $11 \mathrm{~N}^{\circ} 6$ \\
\hline & & \multirow{3}{*}{ Relativas al comportamiento posterior del imputado } & Art. $11 \mathrm{~N}^{\circ} 7$ \\
\hline & & & Art. $11 \mathrm{~N}^{\circ} 8$ \\
\hline & & & Art. $11 \mathrm{~N}^{\circ} 9$ \\
\hline
\end{tabular}

Por su parte, el catálogo de las circunstancias agravantes tendría que organizarse de la siguiente manera:

\footnotetext{
${ }^{6}$ Véase supra, nota 3.
} 


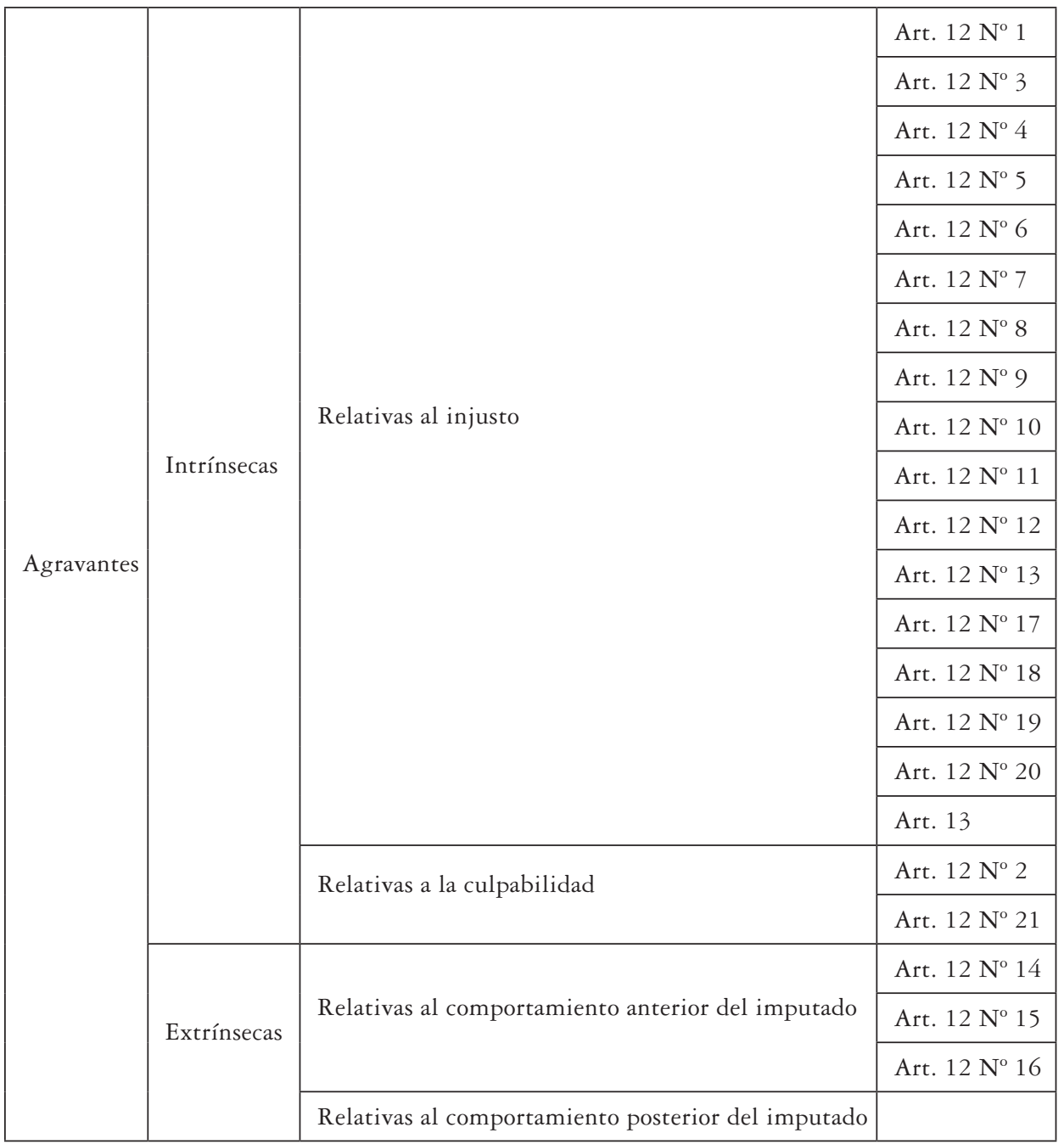

II. LA ESPECIFICIDAD DE LAS ATENUANTES RELATIVAS AL COMPORTAMIENTO PROCESAL DEL IMPUTADO

1. El comportamiento procesal del imputado como objeto de referencia de las atenuantes del $N^{o} 8$ y el $N^{o} 9$ del artículo 11 del Código Penal

Es importante constatar la asimetría que muestra la clasificación de las circunstancias agravantes que exhiben el estatus de circunstancias extrínsecas. Pues el dato que la regulación impone, a este respecto, consiste en el hecho de que las agravantes de esa índole, legislativamente reconocidas como tales, están exclusivamente constituidas por circunstancias relativas al comportamiento anterior del imputado. Ello se traduce en 
que la regulación vigente conoce circunstancias modificatorias (extrínsecas) referidas al comportamiento posterior del imputado solo en la forma de atenuantes. Y como habrá de mostrarse más adelante, en ello es posible encontrar una pista acerca del fundamento sustantivo que subyace a la consagración de estas últimas como factores de determinación de la pena.

En relación con las tres circunstancias atenuantes del catálogo del art. 11 que se hallan referidas al comportamiento posterior al hecho punible por parte del imputado es posible introducir una subdistinción, en atención a si el comportamiento de cuyo efecto atenuante se trata tiene como específico contexto el proceso penal en el marco del cual se lo ha declarado responsable en relación con el hecho que se le imputara. Pues de esas tres circunstancias atenuantes, dos descansan en tal presupuesto, a saber: las establecidas en el $\mathrm{N}^{\circ} 8$ y el $\mathrm{N}^{\circ} 9$ del art. 11. A diferencia de estas últimas, la atenuante del $\mathrm{N}^{\circ} 7$, en tanto consiste en que el imputado haya "procurado con celo reparar el mal causado o impedir sus ulteriores perniciosas consecuencias”, está referida a una forma de comportamiento posterior al hecho punible que es, empero, conceptualmente independiente del proceso penal en el marco del cual se le imputa el hecho en cuestión. Esto no obsta, ciertamente, a que la atenuante del $\mathrm{N}^{\circ} 7$ del art. 11 se deje racionalizar por referencia a un fundamento material compartido por las circunstancias del $\mathrm{N}^{\circ} 8$ y el $\mathrm{N}^{\circ} 9$.

\section{2. ¿Incentivo politico-criminal como fundamento de las atenuantes referidas al comportamiento procesal del imputado?}

Un sector de la doctrina tiende a identificar el fundamento del efecto atenuante reconocido al comportamiento procesal del imputado con un incentivo de índole "premial” a su contribución al establecimiento judicial de su responsabilidad jurídico-penal, esto es, a la facilitación procesal de su propia condena ${ }^{7}$. Identificado así el correspondiente género próximo, la diferencia específica entre una y otra atenuante radicaría en la modalidad que exhibiría semejante contribución procesal del imputado: mientras la atenuante del $\mathrm{N}^{\circ} 8$ del art. 11 premiaría la prestación del imputado consistente en la facilitación de la decisión condenatoria por vía de denunciarse y confesar el hecho punible que le es imputable, la atenuante del $\mathrm{N}^{\circ} 9$ premiaría la prestación consistente en una "colaboración sustancial" al esclarecimiento de los hechos.

Aquí no interesa todavía entrar en la demarcación detallada de una y otra atenuante, sino solo en el mérito de la tesis que hace suya la doctrina dominante en cuanto al fundamento material sobre el cual reposan una y otra regla, tesis que aparece inequívocamente

${ }^{7}$ Véase Garrido, M., Derecho Penal Parte General, 2a ed., tomo I, Editorial Jurídica, 2005, pp. 197, 200 ss.; Matus, J., "Comentario al artículo 11", en Politoff, S. y Ortiz, L. (dirs.), Texto y comentario del Código Penal chileno, Editorial Jurídica, 2002, pp. 182, 184. Véase sin embargo Cury, E., Derecho Penal Parte General, $7^{\text {a }}$ ed., Ediciones U. Católica, 2005, pp. 494 s., 496 s., quien defiende la tesis de que las atenuantes del $\mathrm{N}^{\circ} 8$ y el $\mathrm{N}^{\circ} 9$ del art. 11 se fundamentarían en un juicio de "exigibilidad disminuida", en la medida en que la facilitación de la acción de la justicia sería expresiva de una personalidad respetuosa del derecho, "de la cual el hecho punible bien puede no haber sido un producto anómalo". 
favorecida por una cierta línea de jurisprudencia. Y según ya se anticipara, ese fundamento tiende a ser identificado con un incentivo, político-criminalmente motivado, a la facilitación del propio juzgamiento conducente a una decisión judicial de condena. Como habrá de mostrarse a continuación, tal tesis resulta insostenible frente a algunas definiciones básicas del ordenamiento jurídico chileno a este respecto.

Para advertir esto último, sin embargo, es indispensable dar cuenta, siquiera mínimamente por el momento, de la diferencia fundamental que exhiben las atenuantes del $\mathrm{N}^{\circ} 8$ y del $\mathrm{N}^{\circ} 9$ del artículo 11. Esta diferencia se deja reconocer en atención a cuál era la formulación original de la regla del art. $11 \mathrm{~N}^{\circ} 9$ a la entrada en vigencia del Código Penal y que -con la única salvedad de la sustitución del término "reo" por el término "procesado" - se preservara íntegramente hasta la modificación introducida por la Ley 19.806 , de 31 de mayo de 2002. Hasta entonces, la respectiva atenuante se configuraba "[s]i del proceso no resulta contra el reo otro antecedente que su espontánea confesión".

Ello podría resultar llamativo, debido a que en el $\mathrm{N}^{\circ} 8$ del art. 11 también aparece una referencia a la "confesión" prestada por el imputado. En contra de las apariencias, empero, no cabía reconocer redundancia alguna en la consagración sucesiva de las dos atenuantes. Pues el sentido en que para una y otra circunstancia modificatoria resultaba relevante la confesión del imputado es enteramente diverso. En efecto, bajo el $\mathrm{N}^{\circ} 8$ del art. 11 lo relevante es, hasta hoy, que el imputado, no obstante haber contado con la posibilidad de eludir la acción judicial por la vía de fugarse u ocultarse, se haya presentado -en la terminología del código: "denunciado"- ante la justicia "confesando el delito", esto es, se haya entregado asumiendo su involucramiento en el hecho respectivo ${ }^{8}$. Bajo la antigua versión del $\mathrm{N}^{\circ}$ 9, en cambio, la "espontánea confesión” del imputado venía en consideración, técnicamente, como medio de prueba; y más precisamente, como el único medio de prueba que sustentase la comprobación judicial de su intervención en el hecho a título de autor, partícipe o encubridor. Esto significa que, en sus propios términos, el comportamiento del imputado que configura la atenuante (todavía hoy) prevista por el $\mathrm{N}^{\circ} 8$ del art. 11 no necesita exhibir relevancia probatoria alguna; antes bien, el efecto de atenuación que el mismo puede desplegar consiste en posibilitar factualmente la acción de la justicia a su respecto. En cambio, la relevancia del comportamiento procesal del imputado con efecto potencialmente atenuante bajo el $\mathrm{N}^{\circ} 9$ del art. 11 quedaba precisamente definida por su significación probatoria cualificada, en el sentido recién indicado.

Como es sabido, la ya mencionada modificación legal introducida por la Ley 19.806 persiguió hacer compatible el régimen de las atenuantes referidas al comportamiento procesal del imputado con el modelo de persecución y juzgamiento establecido en el Código Procesal Penal ${ }^{9}$. En lo fundamental, las disposiciones determinantes de este

${ }^{8}$ Véase Etcheberry, A., Derecho Penal Parte General, $3^{\mathrm{a}}$ ed., tomo II, Editorial Jurídica, 1997, p. 26; Mera, J., "Comentario a los artículos 11 No 8-9", en Couso, J. y Hernández, H. (coords.), Código Penal Comentado, tomo I, Legal Publishing, 2011, p. 304.

${ }^{9}$ Véase al respecto González, J.M., "La circunstancia atenuante del artículo 11 No 9 del Código Penal y su evolución legislativa: desde la confesión espontánea a la colaboración sustancial”, en Gaceta Jurídica, No 318, 2006, pp. 12 ss., 15 ss. 
último cuerpo legal son el art. 93 g), el art. 98 y el inc. final del art. 340 . El art. 93 consagra el derecho del imputado a "guardar silencio y, en caso de consentir prestar declaración, a no hacerlo bajo juramento”; por su parte, el art. 98 define el estatus y el régimen de la declaración del imputado como "medio de defensa"; finalmente, el inc. final del art. 340 establece una regla que obsta al pronunciamiento de una sentencia condenatoria que estuviere fundada "en el solo mérito de su declaración". Este decidido destronamiento legislativo de la confesión de su sitial de "reina de las pruebas", operado por medio de la entrada en vigencia del Código Procesal Penal, llevó a que, poco tiempo después, el legislador se convenciera de la necesidad de suprimir la atenuante hasta entonces contemplada en el $\mathrm{N}^{\circ} 9$ del art. 11 del Código Penal, cuyo lugar pasó a quedar ocupado por la atenuante de colaboración sustancial al esclarecimiento de los hechos.

Bajo el derecho actualmente vigente, en consecuencia, sigue siendo en el $\mathrm{N}^{\circ} 9$ del art. 11 del Código Penal donde se encuentra reconocida una atenuante referida a una contribución probatoriamente relevante por parte del imputado. En contraposición a esta, la atenuante del $\mathrm{N}^{\circ} 8 \mathrm{del}$ mismo art. 11, asimismo referida al comportamiento procesal del imputado, halla su fundamento en una facilitación de la persecución por parte del mismo, de índole puramente factual. Y porque la regulación procesal hoy vigente impide que la imputación judicial del hecho punible -aun cuando la existencia de este hubiese sido comprobada por otra vía- pueda apoyarse en nada más que la declaración eventualmente prestada por la persona del imputado, parece manifiestamente equívoco identificar el fundamento de la atenuante del art. $11 \mathrm{~N}^{\circ} 9$ con un incentivo dirigido al imputado en orden a que este facilite el accionar de la justicia por la vía de emitir una declaración autoinculpatoria, y ya en términos tales que el carácter sustancial de la colaboración así efectuada hubiera de depender del hecho de que su declaración resulte indispensable para fundamentar la eventual decisión condenatoria.

Por ello, resulta imprescindible explorar la posibilidad de una fundamentación alternativa del efecto atenuante que la ley reconoce a la contribución procesal, sea factual (bajo el $\mathrm{N}^{\circ} 8$ del art. 11), sea probatoria (bajo el $\mathrm{N}^{\circ} 9$ del art. 11), desplegada por el imputado.

\section{El carácter supererogatorio del comportamiento procesal del imputado como fundamento de atenuación}

La posibilidad de ofrecer una fundamentación alternativa del efecto atenuante que la ley atribuye al comportamiento procesal del imputado que facilita el accionar de la justicia, ha quedado circunscrita al esfuerzo de Cury por identificar ese fundamento con un supuesto juicio de "exigibilidad disminuida"10. Desde ya, hay que advertir que la tesis de Cury supone redefinir el estatus de las atenuantes en cuestión, a saber: como circunstancias modificatorias referidas a (una disminución de) la culpabilidad, y

${ }^{10}$ Cury, E., Derecho Penal Parte General, $7^{\text {a }}$ ed., Ediciones U. Católica, 2005, pp. 494 ss., 496 ss. 
en tal medida intrínsecas al respectivo hecho punible ${ }^{11}$. Sin embargo, el presupuesto argumentativo de la tesis resulta ser altamente débil. El presupuesto consiste en que el comportamiento procesalmente colaborativo del imputado exhibiría relevancia como criterio de evidencia de que el comportamiento de esa misma persona, constitutivo del respectivo hecho punible, no sería expresivo de su genuina identidad -en palabras de Cury: la identidad de "una persona respetuosa de los mandatos y las prohibiciones del derecho"-, lo que a su vez sugeriría que "el hecho punible bien pudo no haber sido sino un producto anómalo, determinado por circunstancias que alteraron el proceso de formación de la voluntad"12.

Si bien al argumento subyace una representación del todo correcta del fundamento último de un posible juicio de exculpación ${ }^{13}$, o en su caso de un posible juicio de atenuación por referencia a la correspondiente causa de exculpación en tanto "eximente incompleta”, el argumento se encuentra enteramente fuera de lugar en lo que aquí interesa. Pues si la relevancia del comportamiento posterior de la persona responsable se restringiera a su función como supuesto criterio de evidencia de la situación motivacionalmente anómala en la que tuvo lugar el hecho punible, la configuración legislativa de las atenuantes respectivas ciertamente habría sido otra; verbigracia, una configuración mucho más próxima a la plasmada en la regla del art. $11 \mathrm{~N}^{\circ} 5$, que inequívocamente instituye una atenuante referida a una situación de alteración motivacional que no alcanza a fundamentar una exclusión de la exigibilidad de una motivación con arreglo a derecho.

Pero de ello no se sigue que el fundamento de las atenuantes del $\mathrm{N}^{\circ} 8$ y el $\mathrm{N}^{\circ} 9$ del art. 11 tenga que ser identificado con un incentivo - político-criminalmente motivado- a la colaboración del imputado para con el éxito de la pretensión punitiva ejercida en su contra. Pues como ya se ha mostrado, tal tesis resulta igualmente implausible, en la medida en que contraviene definiciones básicas del régimen procesal penal vigente, en atención a las cuales, por lo demás, fuera sustituida la atenuante consistente en la "espontánea confesión" del imputado por la atenuante consistente en su colaboración sustancial al esclarecimiento de los hechos. Antes bien, y respetando su categorización como circunstancias extrínsecas, el fundamento de las atenuantes del $\mathrm{N}^{\circ} 8$ y el $\mathrm{N}^{\circ} 9$ del art. 11 ha de ser identificado con la valoración jurídica del comportamiento procesal del imputado como una instancia de prestación supererogatoria de su parte ${ }^{14}$.

Un comportamiento se deja caracterizar como supererogatorio cuando el mismo consiste en una prestación que excede lo que, en la respectiva situación, es posible exigir

${ }^{11}$ Véase supra, I.1.

12 Cury, E., Derecho Penal Parte General, $7^{\text {a }}$ ed., Ediciones U. Católica, 2005, p. 495.

13 Véase Mañalich, J.P., "El estado de necesidad exculpante. Una propuesta de interpretación del artículo 10 No 11 del Código Penal chileno", en Van Weezel, A. (ed.), Humanizar y renovar el derecho penal. Estudios en memoria de Enrique Cury, Legal Publishing, 2013, pp. 723 ss., 727 ss.

${ }^{14}$ Esta tesis se encuentra sugerida ya en Mañalich, J.P., "Determinación y ejecución de la pena", en Revista de Derecho de la UAI, $\mathrm{N}^{\circ} 3,2013$, pp. 309 ss., precisamente en referencia a los dos atenuantes aquí consideradas; en referencia a la atenuante del art. $11 \mathrm{~N}^{\circ} 7$, véase asimismo Mañalich, J.P., "Determinación y ejecución de la pena”, en Revista de Derecho de la UAI, N 2, 2005, pp. 516 ss. 
del agente. De ahí que en la literatura filosófica referida al problema sea usual que el concepto de supererogación sea asociado con aquello que se encuentra "más allá del llamado del deber" ${ }^{15}$. Aquí no es posible, pero tampoco necesario, ofrecer una indagación pormenorizada en los derroteros de la discusión filosófica acerca del estatus normativo de la supererogación. Pero es importante hacer explícita la conexión que en el marco de esa misma discusión suele reconocerse entre las nociones de supererogación y altruismo. Pues una nota distintiva de aquello que puede contar como una instancia de comportamiento supererogatorio consiste, precisamente, en el hecho de que ese comportamiento se oriente al bienestar de sujetos de intereses distintos del agente. En tal medida, es característico de la supererogación que la respectiva prestación supererogatoria muestre una especie de "prescindencia de sí mismo" por parte del agente.

Es crucial, sin embargo, no confundir esta caracterización objetiva del significado de una prestación supererogatoria como tal, por un lado, con la base motivacional que puede explicar su realización por parte del agente, por otro. Esta distinción es de especial importancia de cara a la posibilidad de que un determinado ordenamiento jurídico pueda conferir relevancia a determinadas formas de comportamiento supererogatorio, verbigracia, por la vía de vincularlas con algún régimen de consecuencias jurídicas. Pues en tal situación será naturalmente posible que cualquier agente expuesto a quedar sometido al respectivo régimen de consecuencias jurídicas pueda efectuar una prestación jurídicamente categorizada -y por ende: estandarizada-como supererogatoria para los efectos de hacer operativa alguna modulación de una o más consecuencias jurídicas que le sea favorable. Y ciertamente, en el marco de un Estado de derecho nada jurídicamente censurable hay en que un agente cualquiera pueda exhibir semejante orientación estratégica frente a la regulación jurídica de su comportamiento y sus consecuencias, sin que lo mismo valga para la posible orientación estratégica del Estado y sus agentes en la aplicación y reforzamiento de esa misma regulación ${ }^{16}$. Tal definición asimétrica de la posición del ciudadano y la posición del Estado frente al derecho, y también frente al derecho penal, es constitutiva de un Estado de derecho.

Pues bien, bajo el catálogo del art. 11 del Código Penal, lo que tienen en común las tres atenuantes (extrínsecas) referidas al comportamiento posterior del imputado es que su establecimiento legislativo se corresponde con la estandarización de formas de comportamiento jurídicamente supererogatorio. Esto significa que se trata de prestaciones cuya descripción legal las convierte en prestaciones que van más allá de lo jurídicamente exigible al imputado de cuya responsabilidad jurídico-penal se trata. En tal medida, la ratio sustantivamente compartida por esas tres atenuantes se deja articular como sigue: el comportamiento posterior al hecho punible por parte del imputado puede llegar a exhibir fuerza atenuante cuando ese comportamiento es expresivo de un

${ }^{15}$ Véase al respecto, y desde diferentes perspectivas, Hurd, H., "Duties Beyond the Call of Duty", en Jahrbuch für Recht und Ethik, No 6, 1998, pp. 3 ss.; Heyd, D., "Supererogation", en Stanford Encyclopedia of Philosophy, 2012, disponible en http://plato.stanford.edu/entries/supererogation/; Jackson, M.W.: "The Nature of Supererogation", en The Journal of Value Inquiry, $\mathrm{N}^{\circ} 20$, passim.

${ }^{16}$ Véase Mañalich, J.P., “La pena como retribución”, en Estudios Públicos, No 108, 2007, pp. 183 ss. 
ejercicio supererogatorio de fidelidad a derecho por parte de quien resulta responsable de un quebrantamiento del derecho, en términos tales que la correspondiente reacción punitiva en cuestión puede verse modulada, de modo favorable al imputado, en atención a esa muestra -tardía- de fidelidad a derecho.

La ventaja capital de esta propuesta de reconstrucción dogmática radica en que de ese modo, y al menos en lo concerniente al catálogo de circunstancias atenuantes del art. 11, se consigue una cierta descompresión de la heterogeneidad del fundamento material de las circunstancias extrínsecas frente a las circunstancias intrínsecas, lo que ciertamente no equivale a hacer colapsar la distinción sistemática entre unas y otras ${ }^{17}$. Pues si las circunstancias modificatorias que cuentan como atenuantes intrínsecas se hallan referidas a los presupuestos de los cuales depende la constitución del hecho con significación delictiva -esto es: el injusto culpable-, que resulta jurídico-penalmente reprochable en tanto expresivo de un déficit de fidelidad al derecho, es comprensible que la ley también pueda reconocer fuerza atenuante al comportamiento posterior del imputado, si ese comportamiento posterior es a su vez constitutivo de una muestra cualificada de fidelidad al derecho por su parte ${ }^{18}$. Y desde este punto de vista, la especificidad de las atenuantes relativas al comportamiento posterior del imputado se halla en que la respectiva muestra cualificada de fidelidad al derecho se identifica con una contribución que excede el margen de lo que es jurídicamente esperable de su parte, esto es: con una contribución jurídicamente supererogatoria.

Tratándose de la circunstancia del $\mathrm{N}^{\circ} 7$, el carácter supererogatorio del comportamiento constitutivo de la atenuante está determinado por el hecho de que la prestación aquí relevante ciertamente no se identifica con una prestación indemnizatoria a la cual pudiera quedar obligado el condenado, en caso de que el hecho punible en cuestión exhibiera al mismo tiempo el carácter de un hecho fundante de responsabilidad (civil) extracontractual. Para esto, es decisiva ya la terminología en la cual se encuentra formulada la disposición, no solo porque bajo esta queda comprendido, junto con la reparación "del mal causado", el impedimento de las "ulteriores perniciosas consecuencias" del comportamiento punible, sino también porque la prestación (reparativa o impeditiva) no se encuentra estandarizada en referencia al resultado de una reparación o un impedimento

\section{Supra, I.1}

18 Nótese que ello favorece una cierta racionalización del reconocimiento de fuerza atenuante a la "irreprochable conducta anterior" por parte del imputado bajo el $\mathrm{N}^{\circ} 6$ del mismo art. 11. Pues si en el comportamiento del imputado anterior al respectivo hecho punible no se registran instancias previas de quebrantamiento del derecho -y bajo la acertada interpretación hoy dominante: constitutivas de un crimen o un simple delito-, ello es indicativo, eo ipso, de una medida biográficamente elevada de fidelidad al derecho. Ciertamente, aquí se encuentra implicada una desviación del régimen de determinación de la pena respecto del principio de culpabilidad por el hecho, esta no resulta problemática, empero, en tanto ella opera a favor del imputado. Desde luego, el argumento no se deja invertir para racionalizar una agravación de responsabilidad por reincidencia, ya que en este último caso la correspondiente desviación del principio de culpabilidad por el hecho, entendido como un estándar de legitimación de la producción y aplicación de las normas de sanción penal, tiene lugar en detrimento de la posición jurídica del imputado. 
exitosos, sino más bien al esfuerzo desplegado por el agente en tal empeño, quien tiene que haber "procurado con celo" realizar tal objetivo ${ }^{19}$.

Tratándose, en cambio, de las circunstancias del $\mathrm{N}^{\circ} 8$ y el $\mathrm{N}^{\circ}$ 9, el carácter jurídicamente supererogatorio del comportamiento -aquí: "procesal"- del imputado se fundamenta en la constatación de que sobre el responsable de un hecho punible no pesa deber jurídico alguno de ponerse a disposición de la justicia asumiendo su involucramiento eventualmente fundante de responsabilidad, o bien de contribuir a la comprobación judicial de las circunstancias que fundamentan esa misma responsabilidad, o bien la responsabilidad de otras personas eventualmente implicadas en la perpetración del hecho. Precisamente tratándose de la atenuante del $\mathrm{N}^{\circ} 9$ del art. 11, su estatus como una circunstancia modificatoria referida a una instancia de comportamiento jurídicamente supererogatorio del imputado ha quedado muy acertadamente plasmada en la siguiente caracterización ofrecida por la Corte de Apelaciones de Antofagasta, extraída de un fallo de 8 de agosto del año en curso, rol $N^{\circ} 222-14$, y que se deja encontrar en varios pronunciamientos previos de parte del mismo tribunal ${ }^{20}$ :

Que [...] con la atenuante de colaboración sustancial al esclarecimiento de los hechos se pretende premiar al imputado que, por vía de aportación de antecedentes, facilita la labor persecutoria del Estado, desarrollando así una actuación a la que no está obligado en modo alguno, desde que tiene derecho a guardar silencio durante todo el procedimiento $\left[\right.$ c. $\left.4^{\circ}\right]$.

Sobre esta base, entonces, es admisible proceder a la determinación precisa de las condiciones de aplicación de una y otra atenuante.

\section{LA COLABORACIÓN SUSTANCIAL AL ESCLARECIMIENTO DE LOS HECHOS COMO PRESTACIÓN SUPEREROGATORIA DEL IMPUTADO}

\section{El "esclarecimiento de los hechos" como objeto de la prestación del imputado}

Según ya se sostuviera, la diferencia fundamental que es sustancial reconocer entre las atenuantes del $\mathrm{N}^{\circ} 8$ y el $\mathrm{N}^{\circ} 9$ del art. 11 se encuentra en la naturaleza específica de la contribución procesal desplegada por el imputado en uno y otro caso: mientras bajo el $\mathrm{N}^{\circ} 8$ se trata de una contribución con relevancia puramente factual, bajo el $\mathrm{N}^{\circ} 9$ se

${ }^{19}$ Según ya se anticipara, para ello es enteramente irrelevante cuál sea el motivo que anime al agente en ese empeño. Véase Garrido, M., Derecho Penal Parte General, 2a ed., tomo I, Editorial Jurídica, 2005, p. 201; Mera, J., “Comentario a los artículos 11 No 8-9”, en Couso, J. y Hernández, H. (coords.), Código Penal Comentado, tomo I, Legal Publishing, 2011, pp. 305 s.

${ }^{20}$ Véase las sentencias pronunciadas por la Corte de Antofagasta con fecha 29 de julio de 2010, rol $\mathrm{N}^{\mathrm{o}}$ 245-2010 (c. $5^{\circ}$ ); con fecha 2 de enero de 2012, rol No 336-2011 (c. $4^{\circ}$ ); con fecha 21 de noviembre de 2005, rol No 160-2005 (c. $12^{\circ}$ ); con fecha 4 de noviembre de 2003, rol No 104-2003 (c. $19^{\circ}$ ); con fecha 29

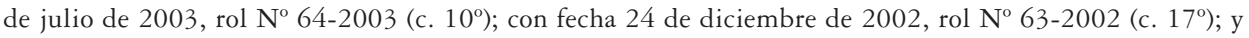
con fecha 30 de noviembre de 2002, rol No 48-2002 (c. $17^{\circ}$ ). 
trata de una contribución con relevancia probatoria. Por supuesto, esto último no debe ser interpretado restrictivamente, en el sentido de que el imputado tendría que proporcionar, por sí mismo, uno o más medios de prueba que lleguen a sustentar, siquiera parcialmente, la decisión condenatoria. Pues es a todas luces suficiente que el imputado suministre antecedentes que hayan de conducir a la obtención de elementos probatorios en los cuales pueda sustentarse la sentencia ${ }^{21}$, sea en lo concerniente a la comprobación del hecho punible, sea en lo concerniente a la intervención del propio imputado o de otras personas en el mismo ${ }^{22}$. En tal medida, lo determinante tampoco es que la contribución del imputado haya resultado ser ex post eficaz para la sustentación probatoria de la decisión judicial ${ }^{23}$, sino más bien el compromiso para con el accionar de la justicia así manifestado ${ }^{24}$. Por supuesto, lo anterior es enteramente consistente con que la disposición legal no circunscriba la oportunidad en la que puede materializarse la contribución del imputado al esclarecimiento de los hechos a una determinada etapa de la investigación o del proceso jurisdiccional propiamente tal ${ }^{25}$. De ahí que el carácter "procesal" de la contribución del imputado tenga que ser entendido lato sensu, en términos tales que la colaboración en cuestión puede ser prestada no solo ante el respectivo tribunal, sino también ante el Ministerio Público, o bien ante agentes policiales ${ }^{26}$.

Precisamente una comprensión de los presupuestos de la atenuante como la recién reseñada fue hecha suya por la Corte Suprema en un relevante pronunciamiento del 29 de abril de 2011, rol No 7153-10, en los siguientes términos:

Que, acorde a lo anterior, como se expresa en la sentencia, entre los antecedentes incriminatorios que cobran relevancia al momento de arribar a la decisión condenatoria, se recurre a la querella del Servicio de Impuestos Internos, que materializa la imputación delictiva que se construye sobre la base de antecedentes documentales que el propio imputado aportó, un informe pericial que se confecciona a partir de la documentación contable del contribuyente, que él mismo adjunta y que permitió desentrañar las irregularidades tributarias que consigna la decisión. También se

${ }^{21}$ Garrido, M., Derecho Penal Parte General, $2^{\mathrm{a}}$ ed., tomo I, Editorial Jurídica, 2005, p. 200.

${ }^{22}$ Véase Mera, J., "Comentario a los artículos 11 No 8-9", en Couso, J. y Hernández, H. (coords.), Código Penal Comentado, tomo I, Legal Publishing, 2011, pp. 305 s.

${ }^{23}$ Lo cual sí es exigido, en cambio, por la regla del art. 22 de la Ley 20.000 para que se configure la atenuante privilegiada de la así -en tal medida: exactamente- llamada "cooperación eficaz".

${ }^{24}$ Véase Cury, E., Derecho Penal Parte General, 7ª ed., Ediciones U. Católica, 2005, p. 497; Garrido, M., Derecho Penal Parte General, 2a ed., tomo I, Editorial Jurídica, 2005, p. 200; Mera, J., "Comentario a los artículos 11 N 8-9”, en Couso, J. y Hernández, H. (coords.), Código Penal Comentado, tomo I, Legal Publishing, 2011, p. 305.

25 Véase Etcheberry, A., Derecho Penal Parte General, $3^{\text {a }}$ ed., tomo II, Editorial Jurídica, 1997, p. 26; Garrido, M., Derecho Penal Parte General, 2 ed., tomo I, Editorial Jurídica, 2005, p. 202; Mera, J., "Comentario a los artículos 11 No 8-9”, en Couso, J. y Hernández, H. (coords.), Código Penal Comentado, tomo I, Legal Publishing, 2011, p. 304.

${ }^{26}$ Así González, J. M., "La circunstancia atenuante del artículo 11 N 9 del Código Penal y su evolución legislativa: desde la confesión espontánea a la colaboración sustancial”, en Gaceta Jurídica, No 318, 2006, p. 18. 
incorporan los testimonios de supuestos proveedores que desconocen la relación comercial que los vincula al incriminado, datos que también se corroboran a partir de anotaciones y respaldos que consigna en su contabilidad.

Para efectos de comprobar la participación del incriminado en los sucesos delictuosos, no obstante su negativa, se llega a la convicción sancionatoria sobre la base de presunciones que, al igual que el hecho punible, surgen desde el análisis de toda la prueba documental y testimonial que se edifica a partir de la documentación contable que el propio encartado aporta. Tal proceder permitió esclarecer el injusto y su participación como autor $\left[\right.$ c. $\left.5^{\circ}\right]$.

Es especialmente significativo que la Corte entienda configurada la atenuante en atención a los antecedentes aportados por el imputado, a pesar de que este negó la responsabilidad que se le atribuía. En efecto, la Corte hace aún más explícito su punto de vista en el considerando inmediatamente siguiente:

Que, como se anticipó, la minorante consagrada en el literal $9^{\circ}$ del artículo 11 del Código Penal procede en el evento que la colaboración del inculpado haya sido de relevancia para la clarificación del suceso. De esta suerte, en este caso, la contribución del encartado expresa una voluntad de participación en la entrega de información, aún [sic] cuando haya negado intervención punible en los hechos [c. $6^{\circ}$ ].

Lo crucial de este último pasaje se encuentra en la consideración de que la negativa, por parte del imputado, de haber intervenido en el hecho punible deja intacta la constatación de su "voluntad de participación en la entrega de información", lo que da cuenta de que la Corte, acertadamente, no reduce la específica significación de la contribución del imputado para con el esclarecimiento de los hechos a su eficacia, sino que la vincula con el reconocimiento del compromiso colaborativo del imputado para con el desarrollo del proceso. Y que la contribución así reconocida al imputado no necesita en modo alguno consistir en una asunción de responsabilidad al modo de una confesión, resulta enteramente confirmado por el hecho de que la Corte entiende configurada la atenuante, según ya se dijo, no obstante la negativa de responsabilidad por parte del mismo imputado.

\section{El carácter "sustancial" de la colaboración: ¿la contribución procesal del imputado como condicio sine qua non para la fundamentación de la condena?}

Pero con la indagación precedente aún no ha quedado clarificado el alcance de la exigencia cuya satisfacción tiende a concentrar buena parte del debate judicial concerniente a la aplicabilidad del art. $11 \mathrm{~N}^{\circ}$ 9, a saber: la exigencia de que la colaboración con el esclarecimiento de los hechos sea "sustancial". Aquí puede ser útil tomar como punto de partida otra toma de posición extraída de un pronunciamiento de la Corte Suprema, plasmado en una sentencia de 3 de enero de 2006, rol No 5741-05. Respecto del alcance de la disposición legal observa la Corte que 
[1] colaboración debe ser sustancial, vale decir, no ha de limitarse a proporcionar detalles intrascendentes, sino constituir un aporte efectivo y serio al éxito de las averiguaciones, aunque no es preciso que se traduzca verdaderamente en resultados concretos [c. $\left.5^{\circ}\right]$.

El pasaje, que por lo demás reproduce una interpretación de la exigencia de sustancialidad de la colaboración que cuenta con importante apoyo doctrinal ${ }^{27}$, refuerza aún más la tesis según la cual no es de la eficacia ex post de la colaboración prestada por el imputado que depende la operatividad de la atenuante, en términos tales -es factible agregar ahora- que es posible reconocer carácter sustancial a una colaboración que en definitiva no lleve, en palabras de la propia Corte Suprema, a "resultados concretos".

Pero esto último contrasta manifiestamente con una tesis interpretativa diferente, que tiende a contar con respaldo en una cierta línea jurisprudencial, según esta el carácter sustancial de la colaboración del imputado equivaldría a su carácter de imprescindible, y más precisamente: de condicio sine qua non para el establecimiento de su responsabilidad por el hecho punible que se le imputa ${ }^{28}$. Esta última orientación interpretativa aparece nítidamente retratada en el pronunciamiento de la Corte de Apelaciones de Antofagasta, de 5 de mayo de 2014, rol No 99-14:

Que en la especie, de los considerandos octavo y noveno del fallo, se desprende la existencia de diversos antecedentes tales como declaraciones de funcionarios aprehensores, escuchas telefónicas, incautación de droga, peritajes, que permitieron tener por acreditada la existencia del hecho punible así como la participación de los acusados, por lo que sus declaraciones no aportaron mayormente a la investigación, pues carecen de la sustancialidad requerida para estos efectos, además que los datos proporcionados por estos no lograron ser comprobables [c. $\left.4^{\circ}\right]$.

Lo decisivo aquí es reparar en la implícita apelación a la fórmula de la así llamada "supresión mental hipotética" a la que parece recurrir la Corte: la existencia de otros antecedentes, de diversa índole, sobre los cuales se deja apoyar la imputación formulada en su contra determinaría la falta de sustancialidad de la colaboración prestada por los imputados.

Semejante interpretación de la exigencia en cuestión es incompatible con el hecho de que el reconocimiento de la atenuante, de acuerdo con la tesis más generalizada en la doctrina y hecha suya por el importante fallo de la Corte Suprema del año 2011, ya

${ }^{27}$ Véase Cury, E., Derecho Penal Parte General, $7^{\mathrm{a}}$ ed., Ediciones U. Católica, 2005, p. 497; Garrido, M., Derecho Penal Parte General, $2^{a}$ ed., tomo I, Editorial Jurídica, 2005, p. 200; Mera, J., "Comentario a los artículos 11 No 8-9”, en Couso, J. y Hernández, H. (coords.), Código Penal Comentado, tomo I, Legal Publishing, 2011, p. 305.

${ }^{28}$ Véase al respecto, González, J.M., "La circunstancia atenuante del artículo 11 No 9 del Código Penal y su evolución legislativa: desde la confesión espontánea a la colaboración sustancial”, en Gaceta Jurídica, No 318, 2006, pp. 19 ss. 
mencionado ${ }^{29}$, no queda supeditado a una simple exigencia de eficacia ex post. Pero aun prescindiendo de esto último, es claro que el recurso a la fórmula de la supresión mental hipotética no puede estimarse adecuado, por la misma razón que la hace impracticable -no obstante la generalizada creencia en sentido contrario- para la comprobación de una relación causal cualquiera. Pues la fórmula en cuestión resulta enteramente inservible tratándose de resultados causalmente sobrecondicionados ${ }^{30}$.

Así, si A dispara un arma de fuego sobre C, al tiempo que B hace lo propio, en circunstancias de que $\mathrm{C}$ resulta muerto inmediatamente, comprobándose que cualquiera de los dos disparos, de no haber estado acompañado del otro, habría bastado para producir la muerte de $\mathrm{C}$ en el preciso instante en que ella de hecho acaeció, entonces ni el disparo efectuado por A ni el disparo efectuado por B cuenta como condición necesaria para la muerte de C. Pero sería a todas luces equívoco - por no decir absurdo- concluir, por ello, que la muerte de $\mathrm{C}$ no ha sido causada por $\mathrm{A}$ ni por B. Antes bien, el problema se disipa si se abandona la definición del concepto de causa basada en la noción de condición necesaria, ello supone abandonar la fórmula de la supresión mental hipotética ${ }^{31}$.

Pues bien, la extrapolación del mismo razonamiento al ámbito que aquí interesa tiene que llevar a descartar la pertinencia de la fórmula de la supresión mental hipotética para la determinación del carácter sustancial que ha de exhibir la colaboración del imputado. Nada inconsistente hay en que la contribución del imputado pueda representar una colaboración sustancial al esclarecimiento de los hechos si, tanto para la determinación del hecho punible como para la determinación de las personas responsables del mismo, el tribunal llega a disponer de medios de pruebas que descansan en antecedentes distintos de los aportados por el imputado. Pues los adjetivos "sustancial" e "imprescindible" están lejos de constituir términos sinónimos. A este respecto, es suficientemente ilustrativo el reciente fallo de la Corte de Apelaciones de Antofagasta de 8 de julio de 2014, recaído en autos rol No 187-14:

Que además, y tal como lo manifestó la abogada defensora en la audiencia del recurso, la declaración del imputado, para que constituya la referida atenuante, no precisa ser única, prioritaria y determinante. Es por ello que no resulta del todo certera, en especial en este caso, la propuesta del recurrente en el sentido que si se suprime la declaración del acusado, igualmente, estaría acreditado el hecho y la participación, porque en tal caso, la colaboración mutaría de sustancial a esencial [c. $6^{\circ}$ ].

Como habrá de examinarse a continuación, empero, este acertado punto de vista está lejos de encontrarse suficientemente generalizado.

\footnotetext{
29 Véase supra, III.1.

${ }^{30}$ En detalle Mañalich, J.P., Norma, causalidad y acción, Marcial Pons, 2014, pp. 39 ss., 43 ss.

${ }^{31}$ Como alternativa a seguir destaca la fórmula de la condición mínima suficiente; véase ibid.
} 


\section{3. ¿Pervivencia latente de la atenuante de "espontánea confesión"?}

En la praxis judicial de reciente data es posible reconocer una distorsión todavía más severa del sentido y alcance del art. $11 \mathrm{~N}^{\circ}$ 9, que consiste en desconocer toda significación a la ya reseñada modificación, introducida el año 2002 por la Ley 19.806, y que de facto conduce a validar la confusión de la exigencia de que la colaboración sea sustancial con la exigencia de que ella sea imprescindible.

La propia Corte Suprema ha abrazado, en algunos fallos, la línea de decisión que aquí se denuncia. En efecto, considérese el siguiente pasaje de su sentencia de 1 de septiembre de 2008, rol No $1342-08$ :

Que, en la perspectiva de la censura formulada, es necesario advertir, además, que al mismo resultado se arriba si se considera el contexto histórico de la enmienda introducida por el artículo $1^{\circ}$ de la ley $\mathrm{N}^{\circ} 19.806$ publicada en el Diario Oficial de treinta y uno de mayo de dos mil dos, al artículo $11 \mathrm{~N}^{\circ} 9$ del cuerpo punitivo, pues no obstante la modificación de su redacción, la alta exigencia que planteaba la norma para aminorar la responsabilidad penal, es decir, que el único medio para acreditar la participación del enjuiciado fuera la confesión espontánea, se mantiene, requiriéndose también hoy que su contribución sea determinante a la hora de la aclaración de los hechos, los que, de otra forma, no pudiesen haber sido comprobados [c. $8^{\circ}$ ].

La misma tesis se encuentra más detalladamente presentada en la posterior sentencia de 17 de junio de 2011, rol No 6204-09:

Entonces, aunque se cambió la redacción del precepto para compatibilizarlo con los nuevos dogmas, conviene resaltar que la alta exigencia que planteaba la norma para aminorar la responsabilidad penal, es decir, que el único medio para acreditar la participación del hechor fuera su confesión espontánea, se mantiene, requiriéndose también hoy que su contribución sea determinante a la hora de clarificar los sucesos que, de otra forma, no pudiesen comprobarse [c. $\left.6^{\circ}\right]$.

Resulta llamativo que la Corte Suprema ni siquiera advierta la necesidad de hacer explícita la radical diferencia de criterio que separa a estos dos pronunciamientos de aquella otra línea de decisión por ella sostenida y ya reseñada. Pues esto conspira directamente contra la factibilidad misma de sostener que en Chile existe auténtica jurisprudencia en el nivel de los pronunciamientos de los tribunales superiores de justicia. Pero aun dejando de lado esta observación más general, lo específicamente preocupante del criterio plasmado en los dos pronunciamientos recién reproducidos se encuentra en que en ellos se atribuye una significación nada más que marginal a la sustitución de la antigua atenuante de confesión espontánea por la nueva atenuante de colaboración sustancial al esclarecimiento de los hechos. Esto, hasta el punto de que en el segundo de los fallos la Corte Suprema llega a sugerir que habría que reconocer la continuidad del "precepto", 
no obstante el "cambio de redacción" que lo afectara en pos de su compatibilización "con los nuevos dogmas".

Para desactivar el malentendido que parece subyacer a esta sugerencia, es imprescindible precisar el uso que se está dando a la expresión "precepto". Pues si por "precepto" se entiende la disposición susceptible de ser identificada como el $\mathrm{N}^{\circ} 9$ del art. 11 del Código Penal, es obvio que después de la modificación legislativa operada el 31 de mayo de 2002 siguió existiendo tal "precepto". Pero si por "precepto" se entiende la norma expresada mediante esa disposición, entonces es claro que el "precepto" vigente a partir del "cambio de redacción” constitutivo de esa misma modificación legislativa es distinto del "precepto" vigente hasta entonces. Y esto determina que sea un sinsentido sostener, como sin embargo lo hace la Corte, que "la alta exigencia que planteaba la norma para aminorar la responsabilidad penal, es decir, que el único medio para acreditar la participación del hechor fuera su confesión espontánea, se mantiene”. Pues compárese el texto de la disposición identificada como el $\mathrm{N}^{\circ} 9$ del art. 11 del Código Penal en su configuración anterior y posterior a la modificación del año 2002:

\begin{tabular}{|c|c|}
\hline Norma vigente hasta el 31.05.2002 & Norma vigente a partir del 31.05 .2002 \\
\hline $\begin{array}{l}\text { Art. 11. Son circunstancias atenuantes: } \\
{[\ldots]} \\
9^{a} \text { Si del proceso no resulta contra el procesado } \\
\text { otro antecedente que su espontánea confesión. }\end{array}$ & $\begin{array}{l}\text { Art. } 11 \text {. Son circunstancias atenuantes: } \\
{[\ldots]} \\
9^{a} \text { Si se ha colaborado sustancialmente al escla- } \\
\text { recimiento de los hechos. }\end{array}$ \\
\hline
\end{tabular}

¿Cómo podría sugerirse medianamente en serio que la exigencia plasmada en la cláusula "no resulta [...] otro antecedente que" pudo conservarse tras la modificación legislativa en cuestión, si en el texto resultante del correspondiente "cambio de redacción" no hay cláusula alguna que pudiera plasmar, siquiera remotamente, semejante exigencia? Lo que la Corte Suprema parece no haber advertido, al sostener el criterio aquí criticado, es que si efectivamente la modificación legislativa pretendió hacer posible un ajuste de la regulación para con "los nuevos dogmas", esto es, con los parámetros de legitimación de la persecución penal fijados por el Código Procesal Penal, entonces ese ajuste no puede sino haberse traducido en que, para exhibir potencial fuerza atenuante, la colaboración procesal del imputado no necesita en modo alguno consistir en la aportación de antecedentes que funjan como condicio sine qua non de la posible decisión condenatoria.

\section{LA DENUNCIA Y CONFESIÓN DEL DELITO COMO PRESTACIÓN SUPEREROGATORIA DEL IMPUTADO}

\section{La posibilidad de elusión de la persecución como presupuesto}

Sobre la base de la reconstrucción ya ofrecida del sentido y alcance del art. $11 \mathrm{~N}^{\circ}$, de acuerdo con su actual configuración, es importante ahora indagar en las consecuencias 
que se siguen de la adopción de la misma estrategia de racionalización a la hora de interpretar el $\mathrm{N}^{\circ} 8$ del art. 11.

Que a diferencia de la atenuante del $\mathrm{N}^{\circ}$ 9, la del $\mathrm{N}^{\circ} 8$ se encuentre referida a una contribución facilitadora de índole puramente factual ${ }^{32}$, determina el sentido preciso que ha de atribuirse a la exigencia de que el imputado haya podido "eludir la acción de la justicia por medio de la fuga u ocultándose" 33 . En efecto, el presupuesto de la atenuante está constituido por la posibilidad con la que ha de contar el imputado para eludir la acción de la justicia a su respecto, posibilidad que ha de servir de contexto, entonces, a la contribución por él prestada, consistente en renunciar a hacer uso de ella, por la vía de haberse "denunciado y confesado el delito". Esta clarificación deviene especialmente importante, porque de ello se sigue que el requisito en cuestión no puede ser disociado de la descripción que la propia disposición legal hace de la contribución del imputado a la que se reconoce efecto atenuante. Pues tal como ya se ha anticipado, esta contribución tiene que ser entendida como consistente en "posibilitar la acción de la justicia pudiendo eludirla" 34 .

Considérese cómo se presentaba el problema a la Corte Suprema en el caso al que se refiere su sentencia (de reemplazo) de 18 de mayo de 2010, rol No 8090-08, en donde la Corte -por voto de mayoría- declaró:

Que lo concerniente a las circunstancias atenuantes de responsabilidad criminal de los numerales octavo y noveno del artículo 11 del Código Penal, que invoca la defensa del enjuiciado, coincidiendo esta Corte con la opinión de la señora Fiscal Judicial, expuesta en el dictamen de fojas 395 y 396, estima también que no concurren los supuestos requeridos por la ley para su aceptación, aunque, en cuanto a la primera, la presentación al tribunal y el reconocimiento que de los hechos hizo el acusado, resultaron tardíos, ya que se había denunciado el delito con anterioridad y se habían reunido antecedentes suficientes y bastantes sobre los hechos imputados [c. $1^{\circ}$.

No es difícil advertir dónde radica el malentendido a partir del cual parece razonar la Corte, a saber: en una incorrecta interpretación de la mención legal de la denuncia de sí mismo que ha de efectuar el imputado, que lleva a la Corte a sostener el carácter supuestamente extemporáneo de su comparecencia y asunción de responsabilidad ante el tribunal en cuestión. Y se trata de un malentendido, toda vez que, por esa vía, la Corte desconoce el carácter puramente factual de la contribución que, por tal vía, ha de prestar el imputado, en tanto contribución facilitadora del actuar de la justicia a su respecto.

32 Véase supra, III.1.

33 Véase Garrido, M., Derecho Penal Parte General, 2a ed., tomo I, Editorial Jurídica, 2005, p. 202; coincidentemente a este respecto ya Novoa, E., Curso de Derecho Penal Chileno, $3^{\text {a }}$ ed., tomo II, Editorial Jurídica, 2003, p. 37; Etcheberry, A., Derecho Penal Parte General, $3^{a}$ ed., tomo II, Editorial Jurídica, 1997, pp. 26 s. Véase en igual sentido, asimismo, Mera, J., "Comentario a los artículos 11 N 8-9", en Couso, J. y Hernández, H. (coords.), Código Penal Comentado, tomo I, Legal Publishing, 2011, p. 304.

${ }^{34}$ Etcheberry, A., Derecho Penal Parte General, $3^{\text {a }}$ ed., tomo II, Editorial Jurídica, 1997, p. 26. 
Notablemente, la interpretación correcta de esa misma exigencia aparece concisamente presentada en el voto de prevención del ministro Künsemüller, quien no compartía

el argumento empleado para rechazar la circunstancia atenuante del artículo 11 $\mathrm{N}^{\circ} 8$ del Código Penal, porque a su juicio, basta que el sujeto comparezca voluntariamente al juicio, aunque este se haya iniciado con anterioridad.

Que esta última resulta ser la tesis correcta, empero, tiene que demostrarse examinando, con mayor precisión, en qué consiste la contribución procesal del imputado asociada a que este se denuncie y confiese el delito.

\section{La denuncia y confesión del delito como prestación del imputado}

La errada interpretación recién denunciada, según ya se anticipara, se encuentra internamente conectada con una comprensión igualmente desacertada del uso que la ley hace de las expresiones verbales "denunciarse" y "confesar" en el contexto del art. 11 $\mathrm{N}^{\circ}$ 8. Pues el concepto de denuncia no ha de ser tomado técnicamente, en el sentido de la correspondiente noción procesal, sino que debe ser entendido como designativo de la acción por la que el imputado se "pone a disposición" de la justicia, esto es, comparece ante ella ${ }^{35}$.

Pero la ley cualifica el sentido preciso de esta autopresentación procesal (lato sensu) del imputado, precisamente por la vía de exigir que este "confiese" el delito. Esto significa que no es acertado asumir que la denuncia y la confesión serían dos requisitos diferenciados; antes bien, se trata de dos aspectos de una y la misma acción, a saber: la de presentarse ante la justicia reconociendo su involucramiento en el hecho punible en cuestión ${ }^{36}$. De ahí que tampoco la noción de confesión pueda ser entendida, en el presente contexto, en el sentido del correspondiente término técnico. Ello explica, por de pronto, que en la doctrina se encuentre extendida la tesis según la cual una así llamada "confesión calificada" -esto es, aquella por la cual el imputado invoca asimismo circunstancias que, de ser efectivas, pudieran eximirlo de responsabilidad- resulta suficiente para la configuración de la atenuante ${ }^{37}$.

Lo crucial, en todo caso, es no perder de vista que la contribución del imputado que configura la atenuante del $\mathrm{N}^{\circ} 8$ del art. 11 no necesita exhibir relevancia probatoria

35 Véase Etcheberry, A., Derecho Penal Parte General, $3^{\text {a }}$ ed., tomo II, Editorial Jurídica, 1997, p. 26; Garrido, M., Derecho Penal Parte General, $2^{a}$ ed., tomo I, Editorial Jurídica, 2005, p. 202. Así ya Novoa, E., Curso de Derecho Penal Chileno, $3^{\text {a }}$ ed., tomo II, Editorial Jurídica, 2003, p. 37, observando acertadamente que la noción de denuncia tampoco aparece usada en "su sentido corriente".

${ }^{36}$ Véase Etcheberry, A., Derecho Penal Parte General, $3^{\text {a }}$ ed., tomo II, Editorial Jurídica, 1997, p. 26.

37 Ibid; Cury, E., Derecho Penal Parte General, $7^{\text {a }}$ ed., Ediciones U. Católica, 2005, p. 495; Garrido, M., Derecho Penal Parte General, $2^{a}$ ed., tomo I, Editorial Jurídica, 2005, p. 202; Mera, J., "Comentario a los artículos 11 N 8-9”, en Couso, J. y Hernández, H. (coords.), Código Penal Comentado, tomo I, Legal Publishing, 2011, pp. 304 s. De otra opinión, empero, Novoa, E., Curso de Derecho Penal Chileno, $3^{\mathrm{a}}$ ed., tomo II, Editorial Jurídica, 2003, pp. 37 s. 
alguna, y ya con total independencia de la redefinición del estatus de la declaración del imputado que trajo consigo la entrada en vigencia del Código Procesal Penal. Pues como se ha mostrado, ello tuvo impacto -como no podía ser de otro modo- en la redefinición de la atenuante referida al comportamiento procesal del imputado que se distingue por exhibir relevancia probatoria, a saber: la del $\mathrm{N}^{\circ} 9$ de ese mismo artículo. La atenuante del $\mathrm{N}^{\circ} 8$, empero, y ya desde la entrada en vigencia del Código Penal, ha estado referida a un comportamiento del imputado cuya contribución para con el accionar de la justicia es puramente factual, y no probatorio, en el sentido ya explicado.

\section{LA COMPATibilidad DE LAS ATENUANTES DEL $\mathrm{N}^{\circ} 8$ Y EL No 9 DEL ART. 11}

El último problema que resta por examinar consiste en la pregunta de si es posible que, en el marco de un mismo proceso, la contribución para con el actuar de la justicia desplegada por el imputado pueda conllevar la configuración tanto de la atenuante del $\mathrm{N}^{\circ} 8$ como de la atenuante del $\mathrm{N}^{\circ} 9$ del art. 11, en términos tales que una y otra puedan operar conjuntamente como factores de determinación de la pena. La pregunta tiene máxima significación práctica, toda vez que, bajo una correcta interpretación de los arts. 65 y siguientes del Código Penal, la concurrencia ya de dos circunstancias atenuantes, no acompañadas de agravante alguna, debe dar lugar a una rebaja de pena en al menos un grado $^{38}$.

La reconstrucción de una y otra circunstancia modificatoria aquí ofrecida hace posible advertir que la pregunta recién planteada tiene que ser respondida afirmativamente. Pues si bien en ambas es reconocible una contribución supererogatoria para con el ejercicio de la persecución penal, una y otra atenuante se diferencian en atención a la específica naturaleza que exhibe la colaboración del imputado: bajo el $\mathrm{N}^{\circ} 8$ se trata de una contribución de índole factual; bajo el $\mathrm{N}^{\circ}$ 9, en cambio, de una contribución con relevancia probatoria ${ }^{39}$. De ahí que sea enteramente posible que una y otra atenuante se configuren en beneficio del mismo imputado en el marco del proceso respectivo, en la medida en que su comportamiento colaborativo exhiba relevancia a ambos títulos.

Este punto de vista ha sido explícitamente validado, por lo demás, por la propia Corte Suprema, en su sentencia de 12 de julio de 2007, rol № 2427-07:

Que el Tribunal acogerá también esta circunstancia ya que las atenuantes del artículo $11 \mathrm{~N}^{\circ} 8$ y 9 del Código Penal se refieren a hechos diferentes. En el presente caso si bien ya se sabía que había participado un segundo sujeto y existía una investigación, no existían antecedentes que a esa fecha involucraran [al acusado], tanto

${ }^{38}$ Para una pormenorizada defensa de esta interpretación, con una crítica de los fundamentos esgrimidos a favor de la tesis del carácter supuestamente facultativo de tal rebaja, véase Mañalich, J.P., “¿Discrecionalidad judicial en la determinación de la pena en caso de concurrencia de circunstancias atenuantes de la responsabilidad penal?", en Informes en Derecho. Doctrina Procesal Penal 2009, DPP, 2010, pp. 49 ss., 54 ss.

39 Supra, III.1.y IV.1. 
así que incluso fue a Investigaciones a realizar un trámite y salió sin problemas de ese lugar, nadie lo asoció al caso, siendo el mismo quien le contó [a un testigo] que él era el segundo individuo que buscaban, [el testigo] con su autorización llama a un detective que conocía para que vaya a conversar con él y se produce el encuentro con la policía, con su confesión. [El acusado] hasta ese momento contaba con el dinero que le había entregado [el otro acusado] y nadie lo buscaba por lo que pudo perfectamente huir y no lo hizo [c. 23].

Es especialmente acertado el razonamiento que la Corte ofrece para concluir que a favor del imputado se configuraba la atenuante del $\mathrm{N}^{\circ} 8$ del art. 11, justamente por el énfasis en el carácter factual de la contribución respectiva, en atención al hecho de que, "nadie lo asoció al caso", habiendo podido "perfectamente huir y no lo hizo". Que el mismo imputado también prestara una contribución con relevancia para el esclarecimiento de los hechos es enteramente independiente de ello, lo que lleva, como correctamente advierte la Corte, a que ambas atenuantes deban ser tenidas por configuradas concurrentemente.

\section{BiBLIOGRAFÍA}

Couso, J., "Comentario previo a los arts. 50 a 69 y 76 a 78", en Couso, J. y Hernández, H. (coords.), Código Penal Comentado, tomo I, Legal Publishing, 2011.

Cury, E., Derecho Penal Parte General, $7^{\mathrm{a}}$ ed., Ediciones U. Católica, 2005.

Etcheberry, A., Derecho Penal Parte General, $3^{a}$ ed., tomo II, Editorial Jurídica, 1997.

Garrido, M., Derecho Penal Parte General, $2^{a}$ ed., tomo I, Editorial Jurídica, 2005.

GonzÁlez, J.M., "La circunstancia atenuante del artículo 11 No 9 del Código Penal y su evolución legislativa: desde la confesión espontánea a la colaboración sustancial”, en Gaceta Jurídica, No 318, 2006.

Heyd, D., "Supererogation", en Stanford Encyclopedia of Philosophy, 2012, disponible en http:// plato.stanford.edu/entries/supererogation/.

Hurd, H., "Duties Beyond the Call of Duty", en Jahrbuch für Recht und Ethik, No 6, 1998.

JACKSON, M.W.: "The Nature of Supererogation”, en The Journal of Value Inquiry, No 20.

MaÑALICH, J.P., “¿Discrecionalidad judicial en la determinación de la pena en caso de concurrencia de circunstancias atenuantes de la responsabilidad penal?", en Informes en Derecho. Doctrina Procesal Penal 2009, DPP, 2010.

MaÑAlich, J.P., "Determinación y ejecución de la pena", en Revista de Derecho de la UAI, No 3 , 2013.

MaÑalich, J.P., "Determinación y ejecución de la pena”, en Revista de Derecho de la UAI, No 2, 2005.

Mañalich, J.P., "El delito como injusto culpable", en Revista de Derecho de la UACh, vol. 24, 2011.

MaÑALICH, J.P., "El estado de necesidad exculpante. Una propuesta de interpretación del artículo $10 \mathrm{~N}^{\circ} 11$ del Código Penal chileno", en Van Weezel, A. (ed.), Humanizar y renovar el derecho penal. Estudios en memoria de Enrique Cury, Legal Publishing, 2013.

MaÑalich, J.P., "La pena como retribución”, en Estudios Públicos, No 108, 2007.

MaÑalich, J.P., Norma, causalidad y acción, Marcial Pons, 2014.

Matus, J., "Comentario al artículo 11", en Politoff, S. y Ortiz, L. (dirs.), Texto y comentario del Código Penal chileno, Editorial Jurídica, 2002. 
Mera, J., "Comentario a los artículos 11 No 8-9”, en Couso, J. y Hernández, H. (coords.), Código Penal Comentado, tomo I, Legal Publishing, 2011.

Novon, E., Curso de Derecho Penal Chileno, $3^{a}$ ed., tomo II, Editorial Jurídica, 2003. 